\title{
Influence of margin design and restorative material on the stress distribution of endocrowns: a 3D finite element analysis
}

Ziting Zheng ${ }^{1}$, Jieli Sun ${ }^{1,2}$, Lifang Jiang ${ }^{1}$, Yuan Wu${ }^{1}$, Jiahui He${ }^{1}$, Wenhao Ruan ${ }^{1}$ and Wenjuan Yan ${ }^{*}$

\begin{abstract}
Background: This study aimed to evaluate the stress distributions in endocrown restorations as applied to endodontically treated teeth (ETT), according to the factors of "margin design" (four levels) and "restorative material" (six levels).

Methods: Four 3D-finite elements models were constructed for endocrown restored molars considering different margin designs. Model A was prepared with a flat butt joint margin and received an endocrown with a 2.0-mm occlusal thickness. Model B was prepared with a $20^{\circ}$ bevel margin and received an endocrown with a $2.0-\mathrm{mm}$ occlusal thickness. Model $\mathrm{C}$ was prepared with an axial reduction and 1-mm shoulder margin and received an endocrown with a 2.0-mm occlusal thickness. Model D was prepared with an anatomic margin and received an endocrown with a 2.0-mm occlusal thickness. The following endocrown materials were used: In-Ceram Zirconia (Zr), Vita Suprinity (VS), IPS Empress (IE), Grandio blocs (GR), VisCalor bulk (VS), and CopraPeek Light (CP). The Load application (600 N) was performed at the food bolus and tooth surface during the closing phase of the chewing cycle. The results for the endocrown and tooth remnants were determined according to the von Mises stress. The failure risk of the cement layer was also calculated based on the normal stress criterion.
\end{abstract}

Results: Model D (with an anatomic margin) showed the greatest stress concentrations, especially in the irregular and sharp angles of the restoration and tooth remnants. The stress concentrated on the dentin was significantly lower in Model B with a $20^{\circ}$ bevel margin (20.86 MPa), i.e., 1.3 times lower than the other three margin designs (27.80 MPa). Restorative materials with higher elastic moduli present higher stress concentrations inside the endocrown and transmit less stress to the cement layer, resulting in lower bonding failure risks. In contrast, materials with an elastic modulus similar to that of dentin presented with a more homogeneous stress distribution on the whole structure.

Conclusions: An endocrown with a $20^{\circ}$ bevel margin design could be a favorable preparation option for ETT. Composite resins (GR and $\mathrm{VC}$ ) exhibit a more even stress distribution, and seem to be more promising materials for endocrown molars.

Keywords: Endocrown, Endodontically treated teeth, 3D finite element analysis, Ceramic, Composite resin

*Correspondence: 645613053@qq.com

1 Department of Stomatology, Nanfang Hospital, Southern Medical

University, Guangzhou, China

Full list of author information is available at the end of the article

\begin{abstract}
Introduction
The decision regarding how to restore endodontically treated teeth (ETT) with extensive coronal loss remains a clinical challenge $[1,2]$. Although satisfactory results have been achieved with crowns supported on post and cores over the years, this process has been revealed to
\end{abstract}


weaken the mechanical resistance of the tooth structure, and to increase the incidence of root fracture [3].

With the emphasis on minimally invasive concepts and progress made in adhesive dentistry, endocrown restorations have been introduced as an alternative option for rehabilitating ETT $[4,5]$. An endocrown restoration is a monolithic restoration that utilizes the pulp chamber and remaining coronal tooth structure as a means of retention [6]. Its advantages include sealing the root canal and preventing the risk of recontamination. Endocrowns have been reported to provide sufficient intention stability and greater fracture resistance [7-9]. Furthermore, clinical studies are available for ETT restored by endocrowns, and show acceptable clinical performance and longevity [10]. Therefore, endocrown restorations have gained higher satisfaction and attention from clinicians and patients.

Studies have shown that margin forms have significant influences on the biomechanical behavior of ETT restored with posts or crowns [11-13]. Whether there is a similar effect from margin design in endocrown restoration is a point for further investigation. Usually, endocrown is designed with a butt joint margin [14]; However, limited scientific evidence is available to support this recommendation. Recent studies found that a ferrule design could provide greater fracture resistance and allow for fewer catastrophic failure modes for teeth restored by endocrowns $[15,16]$. Others have suggested an anatomical margin design with the advantage of the maximum preservation of the tooth structure and morphology [17]. To date, relatively few studies are available to confirm which margin designs of endocrown are more effective for restoring ETT.

Endocrowns are commonly fabricated using ceramic based on leucite ceramics, lithium disilicate, and zirconia. Although ceramics show excellent mechanical properties, they are prone to non-repairable fractures extending to the root, owing to their brittle characteristics $[18,19]$. Given this, alternative materials with a more compliant behavior have been introduced for endocrown fabrication, such as resin composites and polymer-infiltrated ceramics. They exhibit higher resilience and more resistance to higher occlusal forces [20,21]. Recently, a modified polyetheretherketone (PEEK) material, with favorable biocompatibility and good adhesion properties to tooth structures, also become a viable option for endocrowns [22]. Recent studies have also demonstrated that endocrowns prepared with distinct restorative materials using a direct technique are more tooth-friendly than ceramic endocrowns, resulting in less aggressive failures $[6,23]$. Thus, the possibility of using materials with elastic moduli from 3.7 to $200 \mathrm{GPa}$ raises the question of how these restorations will behave mechanically.
Understanding the mechanical behaviors of the different materials used in the fabrication of endocrowns is important.

Finite element analysis (FEA) has been used in dentistry to evaluate the stress distributions generated by masticatory loads, owing to its standardization and effectiveness. It can detect stress concentration regions where failures may occur. Usually, the failure origin consists of points of greater stress concentrations, as previously confirmed by FEAs [19, 24-27]. Therefore, the purpose of this study was to evaluate the influences of the margin design and material type on the biomechanical behaviors of endocrowns for restoring ETT using FEA. The null hypotheses were that the margin design and type of restorative material would not interfere in the stress distribution of the endocrown restoration.

\section{Materials and methods}

This work was approved by the ethics committee of Nanfang Hospital, Southern Medical University, Guangzhou, PR China (NFEC-2017-141). An intact extracted mandibular first molar was scanned using microcomputed tomographic imaging (Quantum GX; PerkinElmer). The obtained data were imported into an interactive medical image control system (Mimics 15.0; Materialise NV, Belgium) in a "Digital Imaging and Communications in Medicine" format. The three-point clouds (enamel, dentin, and pulp) were separated according to the different pixel densities. The contour for each portion was then generated using software (Geomagic Studio; Geomagic Inc). A three-dimensional solid model was then reconstructed with a computer-aided design software program (SolidWorks 2014; Dassault Systèmes). To simulate an endodontically treated molar, the pulp in the root canal was replaced with gutta percha, and a flowable resin (SDR; Dentsply Sirona) was used to fill the pulp chamber floor [27].

Stating from the endodontically treated molar model, four endocrown restored models with different margin designs were created (Fig. 1). Model A was prepared with a flat butt joint margin, and received an endocrown with a $2.0-\mathrm{mm}$ occlusal thickness (Fig. 1A); Model B was prepared with a $20^{\circ}$ bevel margin and received an endocrown with a 2.0-mm occlusal thickness (Fig. 1B); Model $\mathrm{C}$ was prepared with an axial reduction and $1-\mathrm{mm}$ shoulder finish line and received an endocrown with a 2.0mm occlusal thickness (Fig. 1C); Model D was prepared with anatomic reduction for all cusps, and received an endocrown with a 2.0-mm occlusal thickness (Fig. 1D). All endocrowns were prepared with a $2.0-\mathrm{mm}$ intracoronal extension with an $8^{\circ}$ wall inclination angle [28]. The cement layer was modeled with a $120-\mu \mathrm{m}$ thickness between the internal surfaces of the restoration 


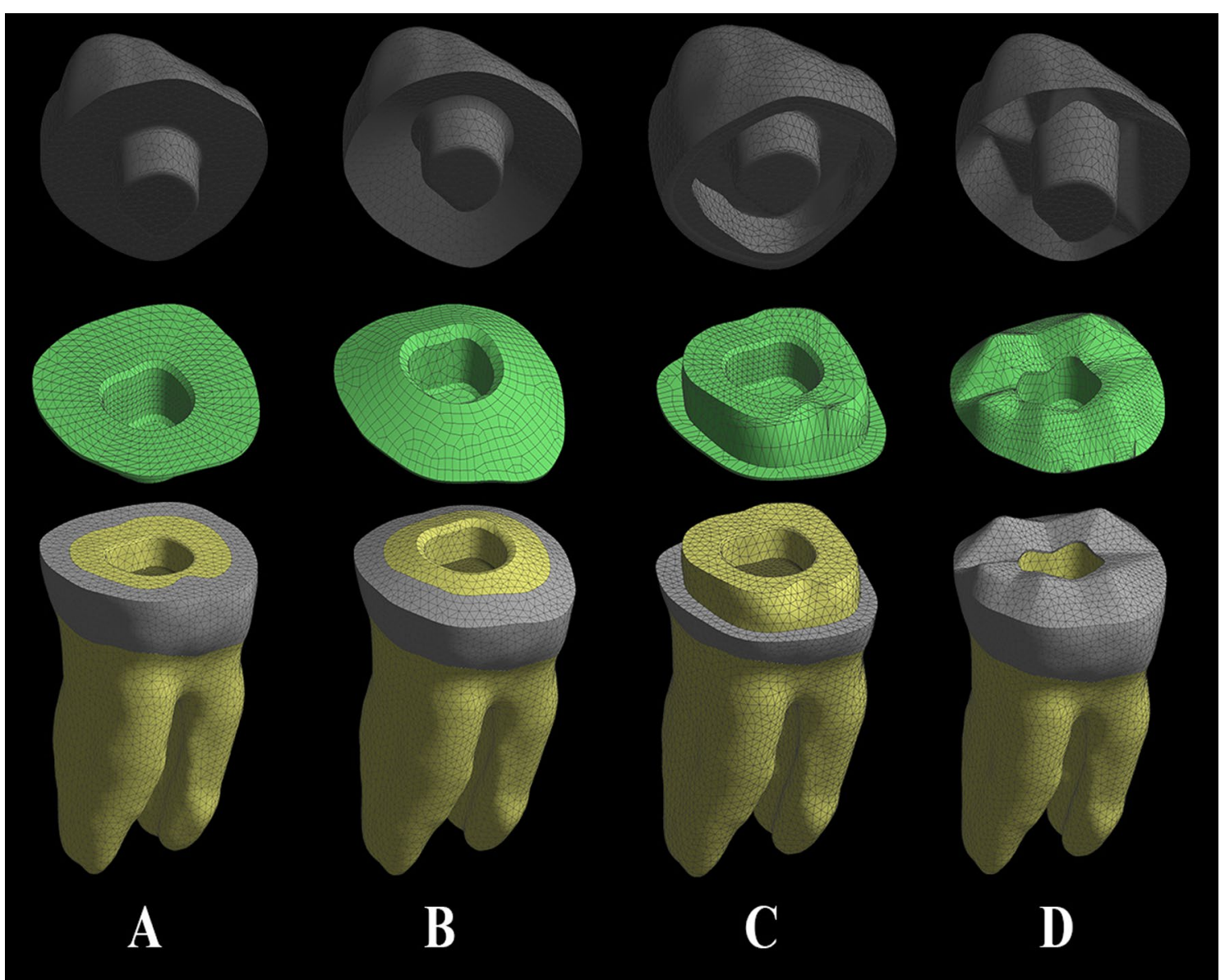

Fig. 1 Finite element models of endodontically treated mandibular molar restored with endocrown using four margin designs. A Flat butt joint margin. B A $20^{\circ}$ bevel margin. C An axial reduction and $1 \mathrm{~mm}$ shoulder margin. D Anatomic occlusal preparation margin

and bonding surfaces of the teeth [24, 29]. The four endocrown-restored models were duplicated and then restored using six restorative materials, including zirconia ceramic (In-Ceram Zirconia, Zr; Vita Zahnfabrik), zirconia-reinforced glass-ceramic (Vita Suprinity, VS; Vita Zahnfabrik), high-leucite content ceramic (IPS Empress, IE; Ivoclar-Vivadent AG), composite resin (Grandio blocs, GR; VOCO), termoviscous bulk-fill composite (VisCalor bulk, VS; VOCO), and PEEK (CopraPeek Light, CP; Whitepeaks).
The geometries were imported in the "Standard for the Exchange of Product Data" format for the ANSYS software CAE (Ansys 20.0; Swanson Analysis Inc); in the software, they were divided into meshes composed of nodes and tetrahedral elements. A convergence test of $10 \%$ mesh control was used to determine the number of elements and nodes to generate four models, as listed in Table 1 . The mechanical properties of the dental structures and materials were determined from published values (Table 2). All structures were assumed to be linearly

Table 1 Number of elements and nodes of four models

\begin{tabular}{llll}
\hline Model & Description & Elements & Nodes \\
\hline A & A flat butt joint margin & 226,159 & 344,603 \\
B & A 20 bevel margin & 227,229 & 347,542 \\
C & An axial reduction and 1 mm shoulder margin & 228,973 & 351,462 \\
D & A 2-mm anatomic occlusal preparation margin & 229,480 & 352,005 \\
\hline
\end{tabular}


Table 2 Material properties

\begin{tabular}{|c|c|c|c|c|}
\hline Material & Elastic modulus (GPa) & Poisson's ratio & $\begin{array}{l}\text { Tensile strength } \\
\text { (MPa) }\end{array}$ & $\begin{array}{l}\text { Adhesive bond } \\
\text { strength to dentin } \\
(\mathrm{MPa})\end{array}$ \\
\hline Enamel [30] & 84.10 & 0.33 & & \\
\hline Dentin [30] & 18.60 & 0.31 & & \\
\hline Gutta percha [20] & $0.69\left(\times 10^{-3}\right)$ & 0.45 & & \\
\hline Periodontal ligament [20] & 0.07 & 0.45 & & \\
\hline Spongious Bone [20] & 1.37 & 0.30 & & \\
\hline Cortical Bone [20] & 13.70 & 0.30 & & \\
\hline In-Ceram Zirconia [24] & 200.00 & 0.31 & & \\
\hline Vita Suprinity [20] & 104.90 & 0.21 & & \\
\hline IPS Empress [24] & 65.50 & 0.20 & & \\
\hline Grandio blocs [20] & 18.00 & 0.26 & & \\
\hline VisCalor bulk ${ }^{a}$ & 12.30 & 0.28 & & \\
\hline CopraPeek Light [31] & 3.70 & 0.40 & & \\
\hline Flowable resin [20] & 7.00 & 0.25 & & \\
\hline Resin cement [29] & 7.40 & 0.35 & $51.90^{\mathrm{a}}$ & $33.80^{\mathrm{a}}$ \\
\hline
\end{tabular}

${ }^{a}$ Supplied by the manufacturer

elastic, isotropic, and homogenously distributed. All contacts were ideally cast.

The load application $(600 \mathrm{~N})$ occurred similar to the methodology described in previous studies [25, 29, 30], and considered the contact between the food bolus and tooth surface during the closing phase of the chewing cycle (Fig. 2). Solid food (apple pulp), with an elastic modulus of $10 \mathrm{MPa}$ and Poisson's ratio of 0.3 , was modeled onto the restoration's occlusal surface. Slide-type contact elements were used between the tooth surface and food, as shown in Fig. 2. In the boundary condition,

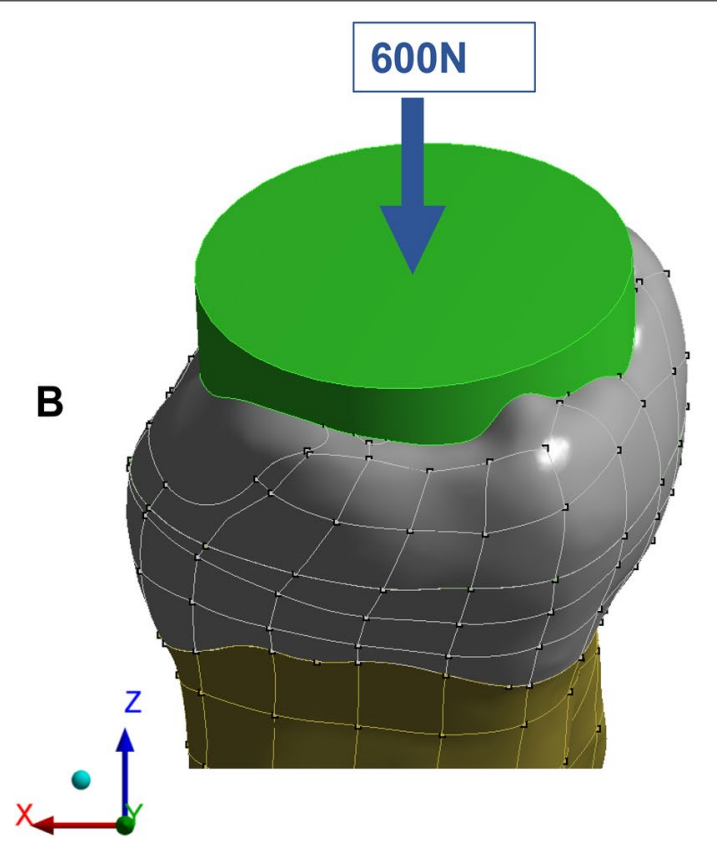

\section{Apple pulp}

L
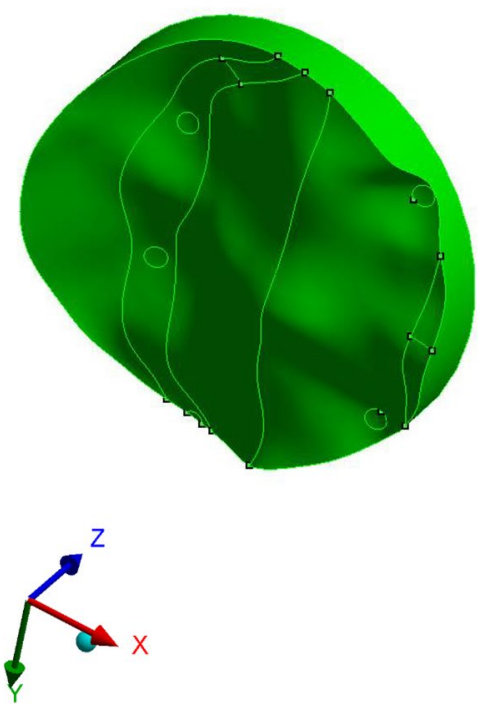

Fig. 2 Food modeling on the occlusal surfaces 
the fixation was applied at the base of the bone tissue and was fixed with zero nodal displacements.

For the restoration and dental structures, the von Mises stress (VMS) was calculated. For the cement layer, the normal stress perpendicular to the insertion trajectory (X-axis) was recorded. In addition, the cohesive and adhesive failure risks for the cement layer were calculated as the stress peak value / tensile strength, and, stress peak value / adhesive bond strength to dentin, respectively [ 25 , $29,32]$.

\section{Results}

The VMS distribution results were obtained for the endocrown (intaglio surface and sagittal cut) and dental remnant structure through colorimetric graphs (Figs. 3, 4, 5). When using $\mathrm{Zr}$ as the restorative material, in the flat butt margin model, the stress was mainly concentrated on the intaglio surface of the endocrown, especially in the axial walls and cavity floor (Fig. 3), the mesial and distal sides of the cervical region of the enamel (Figs. 4, 5), and the furcation area and distal side of the dentin (Fig. 5). In the $20^{\circ}$ bevel margin model, the regions where the VMS was concentrated in the restoration and enamel were similar to those in the flat butt margin model. However, the stress was significantly decreased in the dentin (Table 3 ). The highest VMS in the rounded shoulder margin model was concentrated around the distal-mesial margin of the enamel, axial walls and shoulder margin of the endocrown. For the anatomic margin model, the stress accumulated in the irregular and sharp angles of the restoration and tooth remnants.

Regardless of the margin types of restoration, when using restorative materials (VS, IE, GR) with a lower elastic modulus than $\mathrm{Zr}$, the VMS remained concentrated in these parts but increased both in the enamel and in the pulp cavity walls of the dentin, and decreased in the restoration (Figs. 3, 4, 5). From the sagittal plane of the overall structures (Fig. 5), it can be seen that GR and VC exhibited a more homogeneous stress distribution. However, for the PEEK (with the elastic modulus much lower than dentin), a greater amount of stress was concentrated on the remnant structures (Fig. 5).

For the cement line, all of the simulated models showed a higher adhesive failure risk (0.14-1.30) in comparison to cohesive failure risk (0.09-0.846) (Table 4). In the $\mathrm{Zr}$ endocrown, the anatomic margin model presented the highest failure risk (7.3\%), at 2.70 times greater than the lowest risk in the $20^{\circ}$ bevel margin model (2.7\%). For the other restorative materials, the failure risks increased in all models and followed a similar trend to that of $\mathrm{Zr}$. Accordingly, it can be seen that the stress peaks and failure risks were decreased with the increase of elastic modulus of the restorative materials used in endocrown for the normal stress criteria.

\section{Discussion}

As an adhesive and conservative coronal restoration, the clinical performance and durability of endocrown not only depend on the available design parameters but are also on the mechanical properties of the restorative materials. In this study, we evaluate the stress distribution of ETT restored with endocrown restorations according to the factors "margin design" (four levels) and "restorative material" (six levels). The results demonstrated that both factors significantly influenced the biomechanical behavior as a function of the endocrown restorations, thus rejecting the null hypotheses.

The stress distribution patterns depend strongly on the functional loads in the FEA study. Previous studies applied an axial load to the occlusal surface based on the tripoidism concept (considered as function contacts) [24, 33-35], resulting in the stress of the restoration always being concentrated on the loading point. In practice, the functional contacts during the chewing cycle are regional, rather than individual points. Furthermore, mastication in oral conditions is a motor activity and can be affected by the texture of the food bolus [36]. Consequently, in this study, the food bolus was applied on the surface of an endocrown that could uniformly distribute the loading for better simulating the chewing process $[25$, 30, 37].

From a minimally invasive standpoint, the anatomic occlusal preparation margin shows the maximum preservation of the tooth structure [38]. However, from the results of the FEA, higher-stress concentrations were observed in the restoration and tooth remnants, particularly occurring in the irregular and sharp angles areas (Figs. 3, 4), making them more susceptible to fracture. For the shoulder margin design, stress was observed in the cavity walls of restoration and the enamel of the cervical region, as well as at the margin interface between the dental tissue and restorations (Fig. 5). This is in accordance with previous studies that proposed the addition of short axial walls with a shoulder finish line could counteract the shear stresses through the walls, and provide a better load distribution through the margin $[15,16]$. Nevertheless, in the meantime, owing to such a stress distribution, there is a greater likelihood of fractures occurring at the margin of the endocrown or in the enamel and leakage around the affected restoration.

Considering the clinical operability, endocrowns prepared with a butt joint margin and $20^{\circ}$ bevel margin are more efficient and less technique sensitive than those based on the other two margins. Furthermore, in this study, greater uniform stress distributed over the 


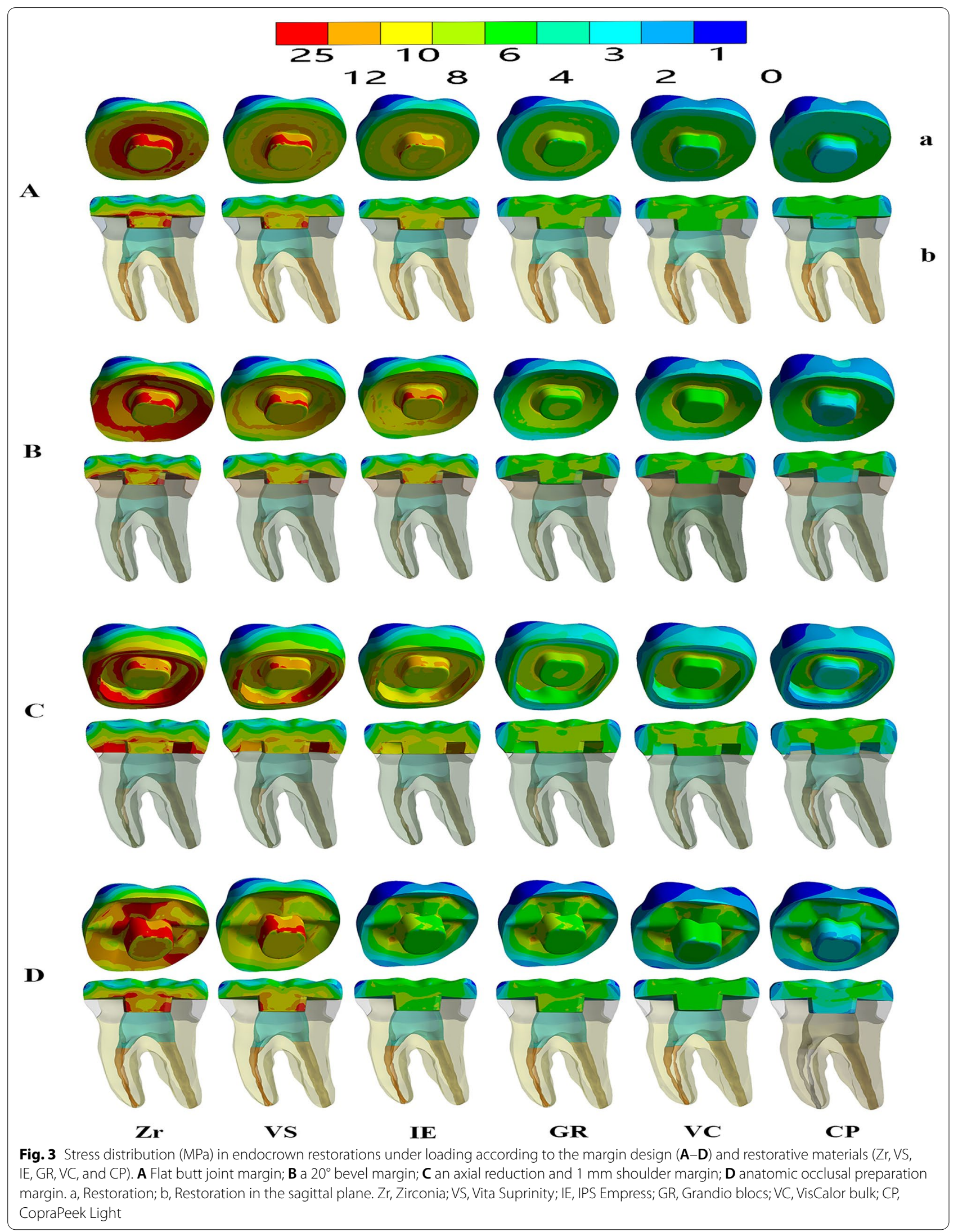




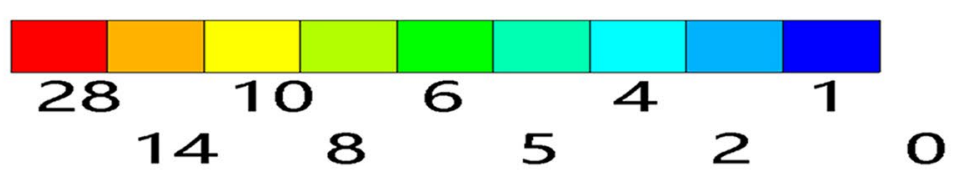

A
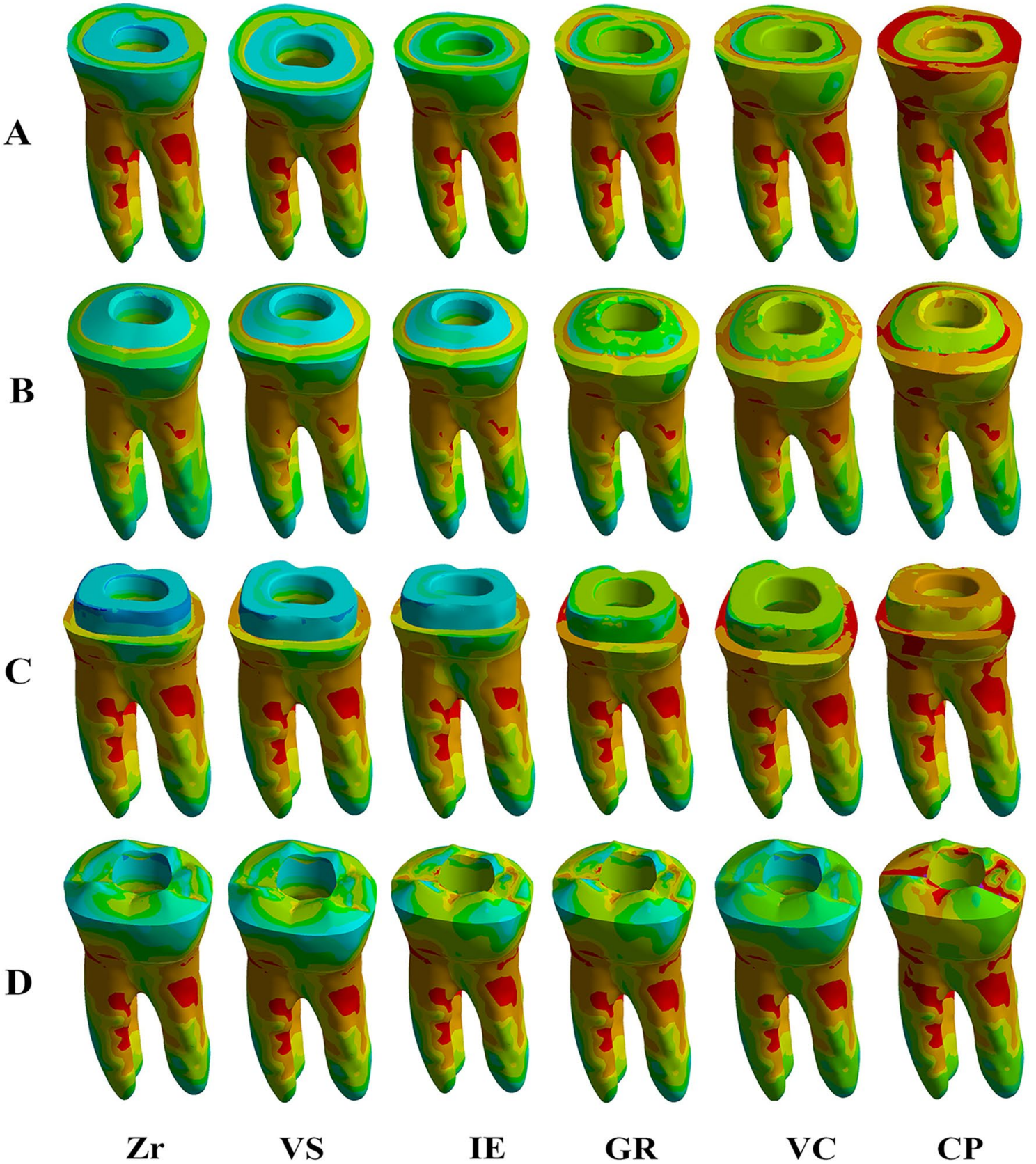

VS

IE

GR

VC

CP

Fig. 4 Stress distribution (MPa) in dental remnant structure under loading according to the margin design (A-D) and restorative materials (Zr, VS, IE, GR, VC, and (P). A Flat butt joint margin; $\mathbf{B}$ a $20^{\circ}$ bevel margin; $\mathbf{C}$ an axial reduction and $1 \mathrm{~mm}$ shoulder margin; $\mathbf{D}$ anatomic occlusal preparation margin. Zr, Zirconia; VS, Vita Suprinity; IE, IPS Empress; GR, Grandio blocs; VC, VisCalor bulk; CP, CopraPeek Light

cervical butt joint and axial walls was observed in the butt joint margin and $20^{\circ}$ bevel margin (Fig. 5). This suggested that a stable surface could better withstand and disperse the stresses through tooth structure [4, $5,14]$. The $20^{\circ}$ bevel margin achieved the lowest VMS peak values in the restoration and remnant structure. 


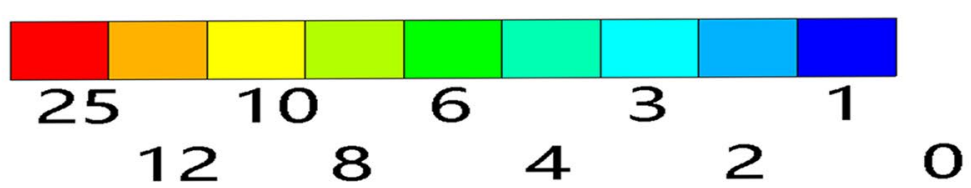

A
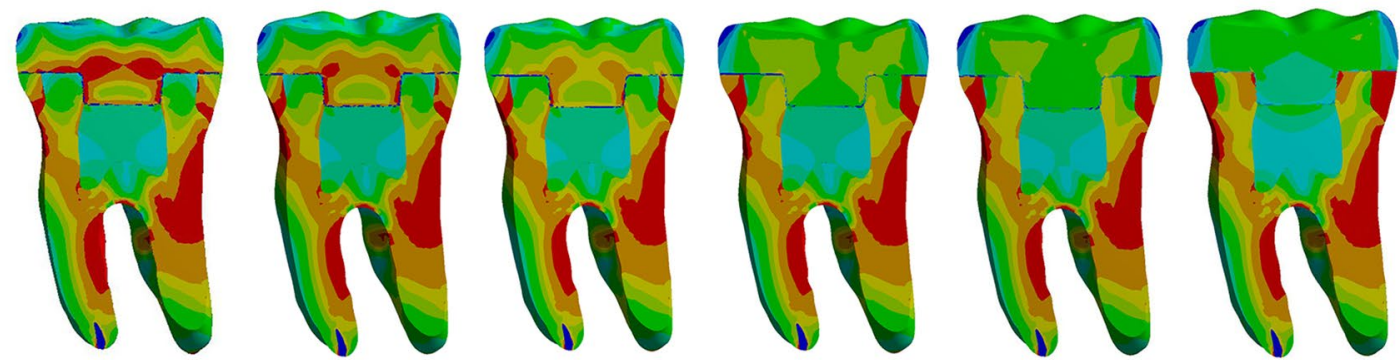

B
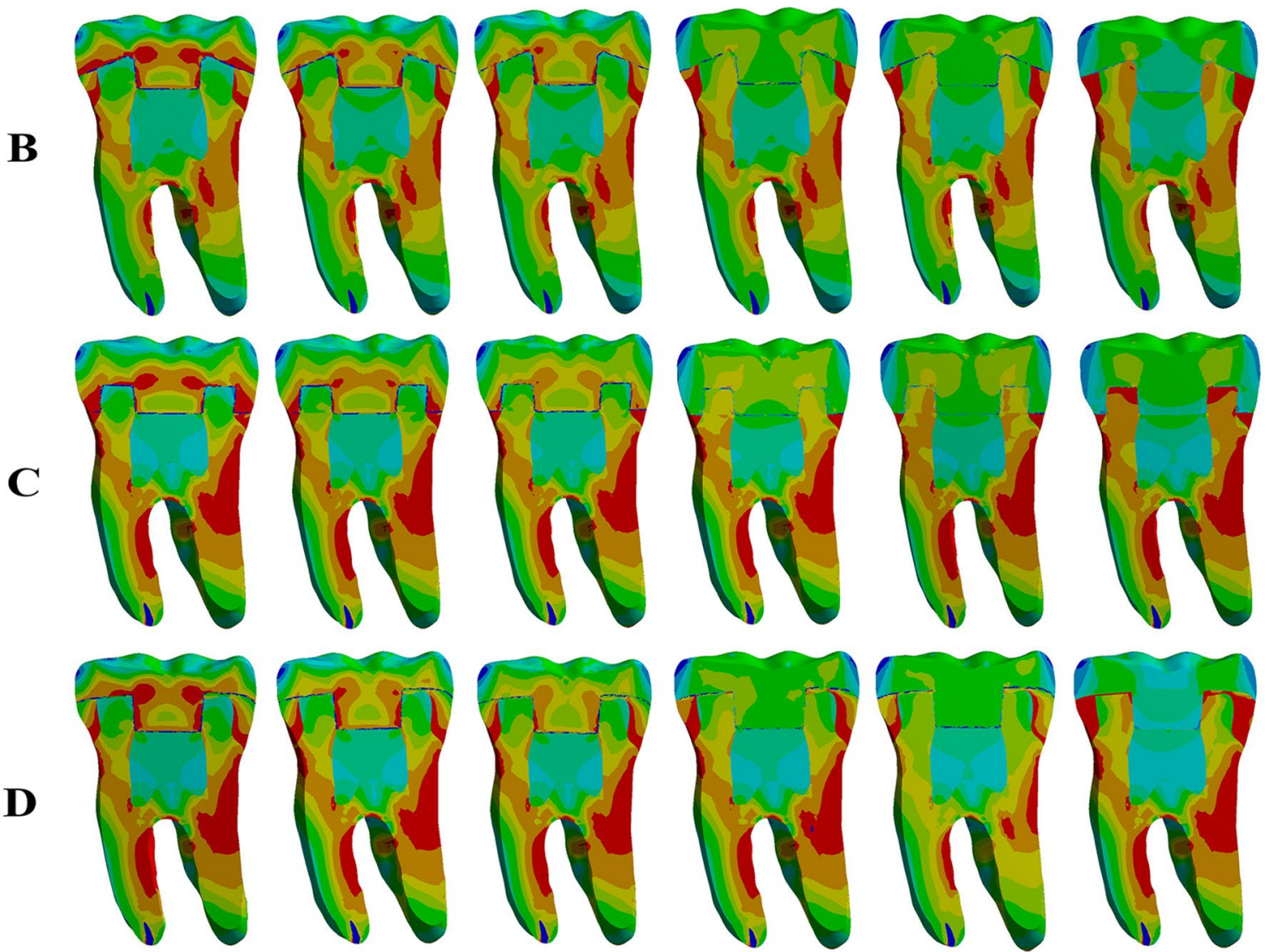

Zr

VS

IE

GR

VC

CP

Fig. 5 Stress distribution (MPa) in overall structures under loading according to the margin design (A-D) and restorative materials (Zr, VS, IE, GR, VC, and (P). A Flat butt joint margin; $\mathbf{B}$ a $20^{\circ}$ bevel margin; $\mathbf{C}$ an axial reduction and $1 \mathrm{~mm}$ shoulder margin; $\mathbf{D}$ anatomic occlusal preparation margin. $Z \mathrm{r}$, Zirconia;VS, Vita Suprinity; IE, IPS Empress; GR, Grandio blocs; VC, VisCalor bulk; CP, CopraPeek Light

Moreover, it presented a more homogeneously stress distribution in the sagittal plane of the overall structures. This implies that a $20^{\circ}$ bevel margin might be better at dispersing the compressive and shear force through the margin, moderating the stress concentrates [39], and reducing the risk of future fracture in ETT.

In this study, the influences of the material type on the stress distributions of endocrown-restored ETT 
Table 3 Group distribution according to the margin forms and restorative material type of the von Mises stress (MPa) obtained in restoration and tooth remnants

\begin{tabular}{|c|c|c|c|c|}
\hline Model & Material & Restoration & Enamel & Dentin \\
\hline \multirow[t]{6}{*}{ A } & $\mathrm{Zr}$ & 26.19 & 17.75 & 27.80 \\
\hline & VS & 24.43 & 17.83 & 27.80 \\
\hline & $\mathrm{IE}$ & 21.89 & 17.93 & 27.79 \\
\hline & GR & 11.36 & 18.38 & 27.79 \\
\hline & VC & 8.94 & 16.43 & 27.79 \\
\hline & $C P$ & 8.46 & 26.40 & 27.78 \\
\hline \multirow[t]{6}{*}{ B } & $\mathrm{Zr}$ & 16.85 & 16.43 & 20.86 \\
\hline & VS & 17.35 & 16.53 & 20.86 \\
\hline & $\mathrm{IE}$ & 16.85 & 16.54 & 20.86 \\
\hline & GR & 9.29 & 18.04 & 20.86 \\
\hline & VC & 9.53 & 18.44 & 20.86 \\
\hline & $\mathrm{CP}$ & 8.47 & 21.94 & 20.86 \\
\hline \multirow[t]{6}{*}{ C } & $\mathrm{Zr}$ & 20.61 & 15.83 & 27.91 \\
\hline & VS & 17.62 & 15.70 & 27.90 \\
\hline & IE & 15.77 & 16.29 & 27.89 \\
\hline & GR & 10.20 & 20.34 & 27.89 \\
\hline & VC & 10.27 & 21.53 & 27.89 \\
\hline & $\mathrm{CP}$ & 8.49 & 25.66 & 27.89 \\
\hline \multirow[t]{6}{*}{ D } & $\mathrm{Zr}$ & 27.94 & 18.00 & 27.83 \\
\hline & VS & 26.06 & 18.12 & 27.83 \\
\hline & IE & 22.11 & 20.15 & 27.83 \\
\hline & $G R$ & 12.61 & 37.95 & 27.82 \\
\hline & VC & 12.78 & 40.27 & 27.82 \\
\hline & $\mathrm{CP}$ & 8.69 & 54.04 & 27.01 \\
\hline
\end{tabular}

A, flat butt joint margin; $B, a 20^{\circ}$ bevel margin; $C$, an axial reduction and $1 \mathrm{~mm}$ shoulder margin; $D$, anatomic occlusal preparation margin. Zr, In-Ceram Zirconia; VS, Vita Suprinity; IE, IPS Empress; GR, Grandio blocs; VC, VisCalor bulk; CP, CopraPeek Light

were also investigated. According to the results, the greater the elastic modulus of the restorative material, the higher the stress peaks observed in the restoration themselves, regardless of the margin types for the restoration. Zr with the highest elastic modulus (200.0 GPa), achieved the highest stress value, i.e., at least three times greater than the lowest value of $\mathrm{CP}$, with the lowest elastic modulus (3.70 GPa). Considering the observed stress peaks (although it does not reach the fracture strength of $\mathrm{Zr}$ ), it may be harmful when located in the lower portion and edge area of the endocrown, where it can easily lead to the failure of the restoration. When evaluating the stresses distribution in a sagittal section, it is possible to observe a stress concentration present on the intaglio surface of the endocrowns, validating the results from previous studies, i.e., that this region is where the propagation of a crack in brittle materials begins [20,35].

According to the literature [24, 29], the cement layer was modeled with a thickness of $120-\mu \mathrm{m}$ in our study.
Table 4 The normal stress peak (MPa), failure risk of cohesive and adhesive for cement layer

\begin{tabular}{|c|c|c|c|c|}
\hline \multirow[t]{2}{*}{ Model } & \multirow[t]{2}{*}{ Material } & \multirow[t]{2}{*}{ Stress peak } & \multicolumn{2}{|c|}{ Failure risk } \\
\hline & & & Cohesive & Cohesive \\
\hline \multirow[t]{6}{*}{ A } & $\mathrm{Zr}$ & 0.55 & 0.011 & 0.016 \\
\hline & VS & 0.71 & 0.014 & 0.021 \\
\hline & IE & 0.88 & 0.017 & 0.026 \\
\hline & $G R$ & 1.42 & 0.027 & 0.042 \\
\hline & VC & 1.63 & 0.031 & 0.048 \\
\hline & $\mathrm{CP}$ & 3.14 & 0.061 & 0.093 \\
\hline \multirow[t]{6}{*}{ B } & $\mathrm{Zr}$ & 0.47 & 0.009 & 0.014 \\
\hline & VS & 0.57 & 0.011 & 0.017 \\
\hline & IE & 0.59 & 0.011 & 0.017 \\
\hline & $G R$ & 1.10 & 0.022 & 0.033 \\
\hline & VC & 1.24 & 0.024 & 0.037 \\
\hline & $\mathrm{CP}$ & 2.43 & 0.047 & 0.072 \\
\hline \multirow[t]{6}{*}{ C } & $\mathrm{Zr}$ & 0.57 & 0.011 & 0.017 \\
\hline & VS & 0.75 & 0.014 & 0.022 \\
\hline & IE & 0.90 & 0.017 & 0.027 \\
\hline & $\mathrm{GR}$ & 1.72 & 0.033 & 0.051 \\
\hline & VC & 1.98 & 0.038 & 0.059 \\
\hline & $C P$ & 4.24 & 0.082 & 0.125 \\
\hline \multirow[t]{6}{*}{ D } & $\mathrm{Zr}$ & 1.48 & 0.029 & 0.044 \\
\hline & VS & 3.02 & 0.058 & 0.089 \\
\hline & IE & 4.15 & 0.080 & 0.123 \\
\hline & $G R$ & 6.66 & 0.128 & 0.197 \\
\hline & VC & 6.85 & 0.132 & 0.203 \\
\hline & $C P$ & 43.93 & 0.846 & 1.300 \\
\hline
\end{tabular}

A, flat butt joint margin; $B, a 20^{\circ}$ bevel margin; $C$, an axial reduction and $1 \mathrm{~mm}$ shoulder margin; $D$, anatomic occlusal preparation margin. Zr, In-Ceram Zirconia; VS, Vita Suprinity; IE, IPS Empress; GR, Grandio blocs; VC, VisCalor bulk; CP, CopraPeek Light

This layer has gradually attracted increased attention, as the bonding failures of this layer are closely related to the longevity of the adhesive restorations. Referring to Table 4, it can be seen that the more rigid the endocrown, the less stress that reaches the cement layer. Referring to Table 4 , it can be seen that the more rigid the endocrown, the less stress that reaches the cement layer. This behavior suggests that the use of materials with higher elastic moduli can minimize the damage to the cement layer, thus decreasing both of the evaluated cement failure risks $[24,32,40]$. Nevertheless, in clinical practice, the cement line is minimal when correct cementation is completed; thus, the differences between the six restorative materials are relatively few, even though they are significant. According to the colored graphs, with a difference of at most $2 \mathrm{MPa}$ (except for the PEEK in group D) with an anatomic margin, it is impossible to predict if they clinically present very different behaviors potentially promoting cement fracture. Despite this limitation, 
materials with a low elastic modulus allow a notable passage of stress to the cement, and therefore, careful cementation should always be performed. Further studies on the cement layer and the corresponding mechanical performance and survival of the endocrown should be conducted.

Regarding the dental remnant structure, it was observed that materials with much higher or lower elastic modulus than dentin seem to transfer more stress to the pulp chamber and axial walls of the dentin. In the PEEK group, the maximum stress was transferred to the dental remnant structure, probably owing to the deformation beyond the material that could not reduce the force transferred to the tooth as a stress breaker. The GR or VC materials, with an elastic modulus more approaching that of dentin were more flexible and dissipated more energy under the same load conditions, Thus, an endocrown made of GR or VC exhibited a more homogeneous stress distribution, as shown in the sagittal plane (Fig. 5). This suggested that only when restorative materials demonstrate an elastic modulus approaching dentin, do they exhibit better biomechanical behavior and less probability of fracture in dental structures. It is of great importance that all parts involved in the rehabilitation (such as the endocrown and remnant dental element), form a cohesive whole, thereby simulating the properties of the dentin-enamel junction, which is guaranteed to have a long-term survival rate. In terms of homogeneously stress dissipation, we suggest that materials with similar modulus to that of dentin would be more compliant in the endocrown approach.

Previous studies found that the available surface of adhesion increased over $47 \%$ by extending the endocrown coverage to the external axial surfaces [15]. However, in this study, no significant difference was observed in the adhesive failure risk between these two margin designs. As shown in Fig. 4, higher stresses were observed in the cervical margin area of the shoulder margin compared with the flat joint margin; this might significantly increase the risks of the debonding of the restoration. In addition, clinical studies have revealed some difficulties during the fabrication of endocrown with shoulder margin, owing to the limited milling area between the pulpal inlay and proximal axial ferrule walls [41]. As such, the butt joint margin presents better protection of the adhesive interface and restoration from detachment.

To the best of our knowledge, this is the first study to fabricate endocrowns using a new-generation bulk-fill composite resin (VC). Compared to conventional composites, $\mathrm{VC}$ is composed of a higher percentage of filler content (83\%). This may have influenced modulus development within the restoration [42], i.e., leading it to exhibit a more compliant biomechanical behavior in the study. Moreover, $\mathrm{VC}$ presents a greater depth of cure and generates less polymerization stress when compared with conventional formulations, thereby, positively influencing the restoration resistance to fatigue [6]. It seems that the use of bulk-fill composite should be considered in the future for the restoration of ETT with the endocrown approach.

Several limitations of this study should be mentioned. The polymerization shrinkage effects of the cement layer were not performed in this FEA. As reported in the literature [33], cement polymerization shrinkage is a centrifugal contraction and may cause a stress concentration in the bonding interface. However, from the FEA results, it seems that polymerization shrinkage of the cement layer has a smaller influence than the endocrown or dental structure for producing stresses, owing to its normal thickness of $120 \mu \mathrm{m}$ in our study [30]. In addition, this study only analyzed the stress distribution of endocrown molars under a static load at the closing phase of the chewing cycle; this cannot accurately represent actual clinical situations. Future studies should consider details such as the polymerization shrinkage of the resinous materials and the results of dynamic loading. Long-term clinical trials are also needed to support the results of the present in vitro study.

\section{Conclusions}

Considering the limitations of the present study, it can be concluded that endocrown designed with a $20^{\circ}$ bevel margin could be the favorable preparation option for endodontically treated teeth. Composite materials (GR and $\mathrm{VC}$ ) with an elastic module more consistent with dentin, presented a more evenly stress distribution, thus being a promising alternative for the manufacture of endocrown restorations.

\section{Abbreviations}

3D: Three dimensional; ETT: Endodontically treated teeth; FEA: Finite element analysis; VMS: Von Mises stress; Zr: In-Ceram Zirconia; VS: Vita Suprinity; IE: IPS Empress; GR: Grandio blocs; VC: VisCalor bulk; PEEK: Polyetheretherketone; CP: CopraPeek Light.

\section{Acknowledgements \\ Not applicable.}

\section{Authors' contributions}

$\mathrm{ZZ}, \mathrm{SJ}$, and YW conceived and designed the study. JL, WY, HJ, and RW performed the finite element analysis. ZZ and SJ wrote the paper. YW reviewed and edited the manuscript. All authors read and approved the final manuscript.

\section{Funding}

This study was supported in part by grants from Natural Science Foundation of Guangdong Province, 2018A0303130213; Clinical Research Startup Program of Southern Medical University by High-level University Construction Funding of Guangdong Provincial Department of Education, LC2016PY023; Clinical Research Program of Nanfang Hospital Southern Medical University, 
2018CR018; Education Research Projects of Nanfang Hospital, Southern Medical University, $17 \mathrm{NJ}-\mathrm{YB} 01$.

\section{Availability of data and materials}

All data generated or analysed during this study are included in this published article [and its supplementary information files].

\section{Declarations}

\section{Ethics approval and consent to participate}

The experimental protocol was established, according to the ethical guidelines of the Helsinki Declaration and was approved by the Human Ethics Committee of Nanfang Hospital, Southern Medical University (NFEC-2017141). Written informed consent was obtained from individual or guardian participants.

\section{Consent for publication}

Not applicable.

\section{Competing interests}

The authors declare that they have no competing interests.

\section{Author details}

'Department of Stomatology, Nanfang Hospital, Southern Medical University, Guangzhou, China. ${ }^{2}$ Department of Stomatology, Beijing Luhe Hospital, Capital Medical University, Beijing, China.

Received: 29 November 2021 Accepted: 27 January 2022 Published online: 05 February 2022

\section{References}

1. Dietschi D, Duc O, Krejci I, Sadan A. Biomechanical considerations for the restoration of endodontically treated teeth: a systematic review of the literature, Part II (Evaluation of fatigue behavior, interfaces, and in vivo studies). Quintessence Int (Berlin, Germany: 1985). 2008;39(2):117-29.

2. Schestatsky R, Dartora G, Felberg R, Spazzin AO, Sarkis-Onofre R, Bacchi $A$, Pereira GKR. Do endodontic retreatment techniques influence the fracture strength of endodontically treated teeth? A systematic review and meta-analysis. J Mech Behav Biomed Mater. 2019:90:306-12.

3. Phang ZY, Quek SHQ, Teoh KH, Tan KBC, Tan K. A retrospective study on the success, survival, and incidence of complications of post-retained restorations in premolars supporting fixed dental prostheses with a mean of 7 years in function. Int J Prosthodont. 2020:33(2):176-83.

4. Sedrez-Porto JA, Rosa WL, da Silva AF, Munchow EA, Pereira-Cenci T. Endocrown restorations: a systematic review and meta-analysis. J Dent. 2016;52:8-14.

5. Govare N, Contrepois M. Endocrowns: a systematic review. J Prosthet Dent. 2020;123(3):411-418 e419.

6. Sedrez-Porto JA, Munchow EA, Cenci MS, Pereira-Cenci T. Which materials would account for a better mechanical behavior for direct endocrown restorations? J Mech Behav Biomed Mater. 2020;103:103592.

7. Biacchi GR, Basting RT. Comparison of fracture strength of endocrowns and glass fiber post-retained conventional crowns. Oper Dent. 2012;37(2):130-6.

8. Guo J, Wang Z, Li X, Sun C, Gao E, Li H. A comparison of the fracture resistances of endodontically treated mandibular premolars restored with endocrowns and glass fiber post-core retained conventional crowns. J Adv Prosthodont. 2016:8(6):489-93.

9. El-Damanhoury HM, Haj-Ali RN, Platt JA. Fracture resistance and microleakage of endocrowns utilizing three CAD-CAM blocks. Oper Dent 2015:40(2):201-10.

10. Belleflamme MM, Geerts SO, Louwette MM, Grenade CF, Vanheusden AJ, Mainjot AK. No post-no core approach to restore severely damaged posterior teeth: An up to 10-year retrospective study of documented endocrown cases. J Dent. 2017:63:1-7.
11. Naumann M, Schmitter M, Frankenberger R, Krastl G. "Ferrule comes first. Post is second!" Fake news and alternative facts? A systematic review. J Endod. 2018:44(2):212-9.

12. Juloski J, Radovic I, Goracci C, Vulicevic ZR, Ferrari M. Ferrule effect: a literature review. J Endod. 2012;38(1):11-9.

13. Magne P, Lazari PC, Carvalho MA, Johnson T, Del Bel Cury AA. Ferruleeffect dominates over use of a fiber post when restoring endodontically treated incisors: an in vitro study. Oper Dent. 2017;42(4):396-406.

14. Sun J, Ruan W, He J, Lin X, Ci B, Yin S, Yan W. Clinical efficacy of different marginal forms of endocrowns: study protocol for a randomized controlled trial. Trials. 2019;20(1):454.

15. Einhorn M, DuVall N, Wajdowicz M, Brewster J, Roberts H. Preparation ferrule design effect on endocrown failure resistance. J Prosthodont. 2019:28(1):e237-42.

16. Pedrollo Lise D, Van Ende A, De Munck J, Umeda Suzuki TY, Cardoso Vieira LC, Van Meerbeek B. Biomechanical behavior of endodontically treated premolars using different preparation designs and CAD/CAM materials. J Dent. 2017:59:54-61.

17. Zimmermann M, Valcanaia A, Neiva G, Mehl A, Fasbinder D. Three-dimensional digital evaluation of the fit of endocrowns fabricated from different CAD/CAM materials. J Prosthodont. 2019;28(2):e504-9.

18. Dartora NR, Maurício Moris IC, Poole SF, Bacchi A, Sousa-Neto MD, SilvaSousa YT, Gomes EA. Mechanical behavior of endocrowns fabricated with different CAD-CAM ceramic systems. J Prosthet Dent. 2020. https://doi. org/10.1016/j.prosdent.2019.11.008.

19. Dartora G, Rocha Pereira GK, Varella de Carvalho R, Zucuni CP, Valandro LF, Cesar PF, Caldas RA, Bacchi A. Comparison of endocrowns made of lithium disilicate glass-ceramic or polymer-infiltrated ceramic networks and direct composite resin restorations: fatique performance and stress distribution. J Mech Behav Biomed Mater. 2019;100:103401.

20. Zheng Z, He Y, Ruan W, Ling Z, Zheng C, Gai Y, Yan W. Biomechanical behavior of endocrown restorations with different CAD-CAM materials: a 3D finite element and in vitro analysis. J Prosthet Dent. 2021;125(6):890-9.

21. Sağlam G, Cengiz S, Karacaer Ö. Marginal adaptation and fracture strength of endocrowns manufactured with different restorative materials: SEM and mechanical evaluation. Microsc Res Tech. 2021;84(2):284-90.

22. Ghajghouj $\mathrm{O}$, Taşar-Faruk S. Evaluation of fracture resistance and microleakage of endocrowns with different intracoronal depths and restorative materials luted with various resin cements. Materials (Basel, Switzerland). 2019;12(16):2528.

23. Sedrez-Porto JA, Münchow EA, Valente LL, Cenci MS, Pereira-Cenci T. New material perspective for endocrown restorations: effects on mechanical performance and fracture behavior. Braz Oral Res. 2019;33:e012.

24. Zhu J, Rong Q, Wang X, Gao X. Influence of remaining tooth structure and restorative material type on stress distribution in endodontically treated maxillary premolars: a finite element analysis. J Prosthet Dent. 2017;117(5):646-55.

25. Dal Piva AMO, Tribst JPM, Borges ALS, Souza R, Bottino MA. CAD-FEA modeling and analysis of different full crown monolithic restorations. Dent Mater. 2018;34(9):1342-50.

26. Cicciu M, Cervino G, Milone D, Risitano G. FEM investigation of the stress distribution over mandibular bone due to screwed overdenture positioned on dental implants. Materials. 2018;11(9):1512.

27. Canto-Naves O, Marimon X, Ferrer M, Cabratosa-Termes J. Comparison between experimental digital image processing and numerical methods for stress analysis in dental implants with different restorative materials. J Mech Behav Biomed Mater. 2021;113:104092.

28. Wang J, Ling Z, Zheng Z, Zheng C, Gai Y, Zeng Y, Zhu X, Chen L, Wu B, Yan $W$. Clinical efficacy of ceramic versus resin-based composite endocrowns in Chinese adults: study protocol for a randomized controlled trial. Trials. 2020;21(1):559

29. He J, Zheng Z, Wu M, Zheng C, Zeng Y, Yan W. Influence of restorative material and cement on the stress distribution of endocrowns: 3D finite element analysis. BMC Oral Health. 2021:21(1):495.

30. Ausiello P, Ciaramella S, Fabianelli A, Gloria A, Martorelli M, Lanzotti A, Watts DC. Mechanical behavior of bulk direct composite versus block composite and lithium disilicate indirect Class II restorations by CAD-FEM modeling. Dent Mater. 2017;33(6):690-701.

31. Anguiano-Sanchez J, Martinez-Romero O, Siller HR, Diaz-Elizondo JA, Flores-Villalba E, Rodriguez CA. Influence of PEEK coating on hip implant 
stress shielding: a finite element analysis. Comput Math Methods Med. 2016;2016:6183679.

32. Tribst JPM, Dal Piva AMO, de Jager N, Bottino MA, de Kok P, Kleverlaan CJ. Full-crown versus endocrown approach: a 3D-analysis of both restorations and the effect of ferrule and restoration material. J Prosthodont. 2021;30(4):335-44.

33. Tribst JPM, Dal Piva AMO, Madruga CFL, Valera MC, Borges ALS, Bresciani E, de Melo RM. Endocrown restorations: influence of dental remnant and restorative material on stress distribution. Dent Mater. 2018;34(10):1466-73.

34. Gulec L, Ulusoy N. Effect of endocrown restorations with different CAD/ CAM materials: 3D finite element and weibull analyses. Biomed Res Int. 2017;2017:5638683.

35. Dartora NR, de Conto Ferreira MB, Moris ICM, Brazao EH, Spazin AO, Sousa-Neto MD, Silva-Sousa YT, Gomes EA. Effect of intracoronal depth of teeth restored with endocrowns on fracture resistance: in vitro and 3-dimensional finite element analysis. J Endodont. 2018;44(7):1179-85.

36. Sterenborg B, Kalaykova SI, Loomans BAC, Huysmans M. Impact of tooth wear on masticatory performance. J Dent. 2018;76:98-101.

37. Ausiello P, Ciaramella S, Di Rienzo A, Lanzotti A, Ventre M, Watts DC. Adhesive class I restorations in sound molar teeth incorporating combined resin-composite and glass ionomer materials: CAD-FE modeling and analysis. Dent Mater. 2019;35(10):1514-22.

38. Vianna A, Prado CJD, Bicalho AA, Pereira R, Neves FDD, Soares CJ. Effect of cavity preparation design and ceramic type on the stress distribution, strain and fracture resistance of CAD/CAM onlays in molars. J Appl Oral Sci. 2018;26:e20180004

39. Xiao W, Chen C, Yang T, Zhu Z. Influence of different marginal forms on endodontically treated posterior teeth restored with lithium disilicate glass-ceramic onlays: two-year follow-up. Int J Prosthodont. 2020:33(1):22-8.

40. Tribst JPM, Lo Giudice R, Dos Santos AFC, Borges ALS, Silva-Concilio LR, Amaral M, Lo Giudice G. Lithium disilicate ceramic endocrown biomechanical response according to different pulp chamber extension angles and filling materials. Materials (Basel). 2021;14(5):1307.

41. Ahmed MAA, Kern M, Mourshed B, Wille S, Chaar MS. Fracture resistance of maxillary premolars restored with different endocrown designs and materials after artificial ageing. J Prosthodont Res. 2021. https://doi.org/ 10.2186/jpr.JPR_D_20_00082.

42. Scribante A, Gallo S, Scarantino S, Dagna A, Poggio C, Colombo M. Exposure of biomimetic composite materials to acidic challenges: influence on flexural resistance and elastic modulus. Biomimetics (Basel). 2020;5(4):56.

\section{Publisher's Note}

Springer Nature remains neutral with regard to jurisdictional claims in published maps and institutional affiliations.
Ready to submit your research? Choose BMC and benefit from:

- fast, convenient online submission

- thorough peer review by experienced researchers in your field

- rapid publication on acceptance

- support for research data, including large and complex data types

- gold Open Access which fosters wider collaboration and increased citations

- maximum visibility for your research: over $100 \mathrm{M}$ website views per year

At BMC, research is always in progress.

Learn more biomedcentral.com/submissions 